\title{
Educação Inclusiva e Alunos com Transtorno Mental: Um Desafio Interdisciplinar
}

\author{
Antonio Carlos Gonsales Sanches ${ }^{1}$ \\ Márcia Aparecida Ferreira de Oliveira \\ Universidade de São Paulo
}

\begin{abstract}
RESUMO - Esse estudo possui seu enfoque nas representações sociais das famílias dos alunos com diagnóstico de Transtorno Mental, frente à perspectiva de sua inclusão em classe comum da rede de ensino e, matriculados em Programa de Educação Especial no município de Indaiatuba, cujo objetivo central era a política sociopedagógica da inclusão. Realizaram-se dois estudos de casos, de natureza descritiva, a partir de entrevistas semi-estruturadas e gravadas, com duas mães com filhos nessa condição. Nos depoimentos, as mães revelaram que os profissionais de educação e saúde passam ao largo das proposições da Educação Inclusiva e, sobretudo, não há discussões intersetoriais e complementaridade de ações que facultam ao aluno o direito de que sua existência-sofrimento seja minimizada e ampliados os contextos sociais inclusivos.
\end{abstract}

Palavras-chave: Educação, Saúde Mental, Inclusão Social

\section{Inclusive Education and Students with a Mental Disorder: An Interdisciplinary Challenge}

\begin{abstract}
This study is focusing on the social representations of families with students with a mental disorder, in the light of their inclusion in a regular school class. The students participated in a special education program in the city of Indaiatuba: the central objective of this program is the inclusion of their students in a regular school class. Two descriptive case studies were realized, based on a recorded, semi-structured interview with the mothers of a program participant. The mothers declared that the education and health professionals ignored the objectives of Inclusive Education and that no intersectoral discussions took place and no complementary actions were taken to reduce the suffering of the students and to broaden the context of their social inclusion.
\end{abstract}

Keywords: Education, Mental Health, Social Inclusion

O movimento denominado de educação inclusiva iniciou-se, mundialmente, no final da década de 1970, fortaleceu-se a partir de 1980 e ganhou ímpeto no início de 1990 (Stainback \& Stainback, 1999; Sassaki, 2003). Foi ampliado por meio da Declaração Mundial sobre a Educação para Todos, ocorrida em Jomtien em 1990 (Unesco, 1990), sendo corroborado com a Declaração de Salamanca e Enquadramento da Acção na Área das Necessidades Educativas Especiais em junho de 1994 (Unesco, 1994).

Na Europa, a implantação de classes e de escolas inclusivas, ocorreu nos países escandinavos, que foram exemplos nos anos da década de 1970. Na Itália, ocorreram movimentos mais radicais, entretanto, na Espanha o processo foi mais gradual. Outros países como: Alemanha, Holanda, Luxemburgo e França acabaram por criar experiências isoladas de prática inclusiva. Nos Estados Unidos e Canadá, inicialmente, ocorreram alguns poucos movimentos para a educação inclusiva (Mittler, 2003; Sassaki, 2003). Parte da literatura que diz respeito às práticas da educação inclusiva começou a surgir na década de 1990 que relatava, basicamente, as experiências que ocorreram a partir do final dos anos de 1980 aos dias de hoje (Sassaki, 2003).

1 Endereço para correspondência: Rua Nápoles, 117, Jardim Bela Vista. Indaiatuba, SP. CEP 13331-097. Fone: (19) 3834.51.33. E-mail: antoncarlgs@hotmail.com.
Em alguns países o movimento da educação inclusiva busca um enfoque que atenda aos alunos deficientes dentro do sistema educativo geral, por outro lado, internacionalmente, tem se entendido a educação inclusiva como uma reforma que possa responder à diversidade entre todos os estudantes (Ainscow, 2005).

$\mathrm{Na}$ realidade brasileira, ainda que, a partir do início da década de 1990, o movimento para a inclusão educacional e as discussões fossem ampliadas, verificou-se pouco ou nenhum avanço no sentido de efetivar a construção de contextos educacionais inclusivos (Prieto, 2003). Por outro lado, alguns autores como Jerusalinsky (1997), Kupfer e Petri (2000), Voltolini (2004), Saraceno (1999), Costa-Rosa; Luzio e Yasui (2003) têm contribuído com estudos, pesquisas, reflexões e proposições sobre as questões que envolvem as problemáticas do indivíduo frente ao sofrimento mental e sua inclusão em um contexto social e educacional amplificado.

Especialmente, a partir de 2003, o Ministério da Educação (MEC), por meio da Secretaria de Educação Especial [SEESP] (Brasil, 2004a), assumiu o compromisso de fomentar e disseminar a política de construção de sistemas educacionais inclusivos, com o propósito de garantir o acesso e a permanência de todas as crianças, jovens e adultos, com necessidades educacionais especiais, no sistema regular de ensino (Brasil, 2004a). 


\section{Deficiência e Transtorno Mental}

Pode-se entender que, de uma forma geral, na terminologia Deficiência, contempla-se e enquadra-se o Transtorno Mental, como citado na Declaração da Guatemala em que:

O termo "deficiência" significa uma restrição física, mental ou sensorial, de natureza permanente ou transitória, que limita a capacidade de exercer uma ou mais atividades essenciais da vida diária, causada ou agravada pelo ambiente econômico e social (Brasil, 2004b, p. 281).

O Decreto n. ${ }^{\circ} 3.298$ de 20 de dezembro de 1999 (Brasil, 2004b), define - "[...] I - deficiência - toda perda ou anormalidade de uma estrutura ou função psicológica, fisiológica ou anatômica que gere incapacidade para o desempenho de atividade, dentro do padrão considerado normal para o ser humano...". No Dicionário Houaiss (Houaiss \& Villar, 2001), encontra-se, "Deficiência s.f. 1 MED insuficiência ou ausência de funcionamento de um órgão $<$ d.glandular $>$ 2 PSIQ insuficiência de uma função psíquica ou intelectual $<$ d.mental $<$ d.sensorial $>$.

É importante, ainda, registrar que, com freqüência, verifica-se na literatura o termo Portador, no entanto, alguns autores questionam essa terminologia, em razão de entender que a palavra "[...] traz implícita a idéia de carregar algo que, por ser 'especial', não cabe no 'lugar-comum'. Pode reforçar a idéia de excluir o diferente ao pressupor uma 'falta' que, talvez, exceda muito sua própria dimensão" (Minto, 2002).

Com a Portaria GM/MS n. ${ }^{\circ} 1.060$ de 5 de junho de 2002, o governo federal aprovou a Política Nacional de Saúde da Pessoa Portadora de Deficiência e, em seu texto, encontra-se, “[...] A situação da assistência à pessoa portadora de deficiência no Brasil ainda apresenta um perfil de fragilidade, desarticulação e descontinuidade de ações nas esfera pública e privada" (Brasil, 2002).

\section{Família e Doença Mental}

A concepção e compreensão atual sobre a estrutura da família nuclear no mundo ocidental estão centradas na afeição e na intensificação das relações entre pais e filhos na privacidade de suas casas (Melman, 2001), começou a se ampliar na Europa, a partir do século XVII, e nesse sentido, amplia e problematiza a concepção de família (Neder, 2002), pois, para ela, não existiria histórica e antropologicamente, um modelo-padrão de organização familiar. Assim, deve-se pensar as famílias de forma plural, para que construa uma democracia baseada na tolerância com as diferenças. Portanto, é nessa idéia das inúmeras possibilidades de formatação de grupos familiares que implicam aceitação, tolerância e, não raro na solidariedade com a singularidade que a presença da diferença remete e, nesse contexto, coloca-se a doença mental. Os significados e representações sobre os transtornos mentais podem não ser compartilhados igualmente por todas as pessoas que vivem numa mesma casa, o que resulta em diferentes atitudes e vivências ante os problemas (Melman, 2001), pois as subjetividades e objetividades de cada componente do grupo familiar que possuem representações e valores diferenciados a respeito do doente mental são determinadas historicamente, e ainda, esse olhar recebe a influência e os reflexos de outros contextos, como a religiosidade, o fator socioeconômico, a cultura e outros. Dessa forma:

$\mathrm{O}$ adoecimento de um membro da família representa, em geral, um forte abalo. Para a maioria das pessoas a enfermidade significa uma grande ruptura na trajetória existencial. A vivência de catástrofe desestrutura as formas habituais de lidar com situações do cotidiano. Muitos familiares não estão preparados para enfrentar os problemas, não sabem como agir. Encarando as dificuldades, tentando explicar o aparecimento da doença, essas pessoas mergulham na turbulência de suas dúvidas e conflitos (Melman, 2001, p. 19-20).

No entanto, a convivência com a doença e o adoecer, seja física ou psiquiátrica, acaba por representar uma dificuldade e um desgaste ao grupo familiar, isso tudo, podendo ser ampliado se este adoecer for longo, com manifestações agudas e, sobretudo, for vivido, como incapacitante e estigmatizador (Cavalheri, 2003). Ao remeter-se às singularidades da doença mental, encontra-se que:

Os transtornos mentais e comportamentais exercem considerável impacto sobre os indivíduos, as famílias e as comunidades. Os indivíduos não só apresentam sintomas inquietadores de seu distúrbio como sofrem também por estarem incapacitados de participar em atividade de trabalho e lazer, muitas vezes em virtude da discriminação. Eles se preocupam pelo fato de não poderem arcar com suas responsabilidades para com a família e os amigos, e temem ser um fardo para os outros (OPAS/OMS, 2001, p. 51).

A situação acaba por sobrecarregar as rotinas familiares, implicando mudanças das atividades diárias desse grupo, como os cuidados com a casa, o trabalho, a escola e os cuidados pessoais. A isso, soma-se o quadro de sintomas que o indivíduo poderá apresentar o que significará cuidados intensivos por parte da família, para acompanhamento em consultas, com a higiene, alimentação, sono, medicação e outros (Cavalheri, 2003).

Assim, a sociedade frente à doença mental e todo o movimento de crítica, desospitalização e afluência da reforma psiquiátrica na atualidade, acabaram por configurar:

uma nova realidade na qual um número cada vez maior de pessoas passaram a ser assistidas em serviços extra-hospitalares. Esses fenômenos introduziram novos elementos no campo de negociação entre famílias e o campo da saúde mental, obrigando as partes implicadas a rediscutir as bases de uma nova relação (Melman, 2001, p. 61).

Nesse sentido, há de se considerar que a real possibilidade de reinserção social do indivíduo com transtorno mental implica envolvimento e comprometimento do grupo familiar e isto, independe como a família se constitui, pois ela continua representando a garantia de sobrevivência e proteção de seus membros (Cavalheri, 2003). Dessa forma, no que diz respeito as relações sociais,

Não é difícil perceber que o processo de inclusão começa na família, pois ela precisa se dar conta da importância de uma pessoa com deficiência ter estreitas e íntimas com as outras, participando da vida normal, integrando-se em grupos sociais 
diversos. Nesse caso, a aceitação por parte dos pais será o fator fundamental para o desenvolvimento da criança ao longo da vida, estimulando a convivência com os demais membros da sociedade, as atividades culturais, esportivas, de lazer e outros (FGV/IBR/CPS, 2004, p. 44).

A importância da valorização das famílias, como um espaço de produção de identidade social básica para qualquer criança, portanto, um lugar de formação de uma cidadania ativa, cuja construção desta identidade seja em seu aspecto individual ou coletivo, deve, também, passar pela tolerância com a diversidade humana (Neder, 2002).

O objeto deste estudo foi um Programa de Educação Especial no município de Indaiatuba e, que possui como objetivo central, a perspectiva da inclusão educacional dos alunos em classes comuns da rede regular de ensino ou, em outras palavras, busca "trabalhar a política sociopedagógica da inclusão” (Ferretti, Milan, \& Sanches, 2004). Entretanto, ainda que um programa de caráter e características educacionais possui em sua estrutura ações e serviços (Classes de Apoio e Oficinas Pedagógicas) que, sob o ponto de vista da educação inclusiva, mantém o aluno deficiente excluído de um contexto socioeducacional regular. Por outro lado, as Salas de Recursos e as Orientações Pedagógicas em Caráter Itinerante do Programa Educação Especial, têm a qualidade de complementar o ensino regular em seus níveis de escolarização, promovendo e auxiliando, assim, no processo de inclusão.

Entre todos os alunos matriculados no Programa deficientes físicos, intelectuais, auditivos, visuais e com dificuldades acentuadas de aprendizagem, fez-se a opção de apoiados no Estudo de Caso, realizar entrevista semi-estruturada e gravada, com a família do aluno com diagnóstico de Transtorno Mental e com acompanhamento psiquiátrico. A unidade de análise [família] é de fundamental importância na vida do indivíduo, pois o grupo familiar é a primeira e importante vinculação afetiva e social da criança, seguida da sua entrada no ambiente socioeducacional da escola. Portanto, nesse contexto, o papel da família é essencial no desenvolvimento da vida escolar do aluno.

É importante ressaltar que, o diagnóstico de Transtorno Mental (OMS, 1993), foi utilizado em razão da Classificação de Transtornos Mentais e de Comportamento da CID-10 ser referência na prática dos serviços de saúde mental no Brasil. No entanto, segundo a Organização Mundial de Saúde (1993),

O termo 'transtorno' é usado [...] de forma a evitar problemas ainda maiores inerentes ao uso de termos tais como 'doença' ou 'enfermidade'. 'Transtorno' não é um termo exato, porém é usado [...] para indicar a existência de um conjunto de sintomas ou comportamentos clinicamente reconhecível associado, na maioria dos casos, a sofrimento e interferência com funções pessoais (OMS, 1993, p. 05).

Por outro lado, frente à utilização corrente de termos como: doença mental e loucura, encontrados na literatura também são utilizados para manter-nos fiel às revisões literárias realizadas e ao socialmente representado. A opção pelo diagnóstico de Transtorno Mental e, em tratamento psiquiátrico, deve-se ao fato de o tema ser um desafio à Educação, suscitando controvérsias na maioria das vezes e, ainda, entender que a própria nosografia psiquiátrica em relação ao doente mental é excludente e responsiva a um processo dialético histórico-estrutural de construção da doença mental.

Por conseguinte, a unidade de análise que foi parte do objeto de estudo: a família do aluno com diagnóstico de Transtorno Mental referiu-se exclusivamente ao aluno com diagnóstico médico inicial nesta categoria e, em tratamento psiquiátrico.

Assim, com a análise da entrevista com o familiar, fundamentada com o conceito das Representações Sociais, sob a perspectiva da Psicologia Social Crítica e com base no enfoque histórico-estrutural da dialética Exclusão/Inclusão, entende-se que haveria a necessidade de se buscar uma resposta à seguinte questão:

Como são as representações sociais da família do aluno com diagnóstico de Transtorno Mental matriculado no Programa de Educação Especial no município de Indaiatuba frente à perspectiva de sua inclusão educacional?

As representações sociais:

... representam, por excelência, o espaço do sujeito social, lutando para dar sentido, interpretar e construir o mundo em que ele se encontra. Para mais além das estruturas dadas da vida social, elas oferecem a possibilidade da novidade, da autonomia, daquilo que ainda não existe, mas poderia existir (Jovchelovitch, 2000, p. 41).

Por outro lado, a construção do objeto de pesquisa é um processo pelo qual o fenômeno de Representação Social é simplificado e tornado compreensível pela teoria, para a finalidade da pesquisa (Sá, 1998).

\section{Método}

\section{Participantes}

Foram entrevistadas duas mães de alunos regularmente matriculados no Programa de Educação Especial, com diagnóstico de Transtorno Mental, conforme a Classificação Internacional de Doenças - 10 [CID-10] (OMS, 1993), e, em tratamento psiquiátrico.

Para que as participantes desta pesquisa tivessem seus direitos resguardados, sem que fossem infringidos os princípios éticos, o presente projeto foi submetido à: (1) Aprovação no Comitê de Ética da Escola de Enfermagem da Universidade de São Paulo; (2) Pedido de autorização institucional à Secretaria Municipal de Educação; (3) Na abordagem inicial aos sujeitos da pesquisa, foi facultada a possibilidade de participarem ou não do estudo e informados, previamente, de que, uma eventual negação, não lhes acarretaria prejuízos. Foram esclarecidos da necessidade da gravação, cada um receberia uma identificação fictícia para manter o anonimato, e os dados contidos nos depoimentos seriam publicados e divulgados em periódicos e eventos científicos nacionais e internacionais. Ao final da abordagem foi esclarecido que a colaboração deles seria relevante aos 
profissionais da educação e da saúde mental; (4) Consentimento Livre e Esclarecido foi obtido com as colaboradoras. Assim, foi importante a leitura do Termo de Consentimento Livre e Esclarecido com as participantes, a fim de clarificar informações que possam ter ficado obscuras. Em seguida, o mesmo foi assinado pelas participantes e pelo pesquisador; (5) Foi firmado compromisso com as participantes de que teriam suas dúvidas, quanto à pesquisa, esclarecidas sempre que necessário.

A primeira análise dos prontuários escolares indicou 15 alunos que, inicialmente, enquadravam-se no diagnóstico de Transtorno Mental e de Comportamento e encontravam-se em assistência psiquiátrica, sendo oito do sexo masculino e sete do feminino. Considerando que, a classificação de Transtornos Mentais e de Comportamento é ampla e implica inúmeras diretrizes diagnósticas, assim, para fins deste estudo, após uma segunda análise dos prontuários dos alunos e novas consultas à Direção e Coordenação do Programa, realizou-se dois Estudos de Casos. Nos dois casos escolhidos, os documentos - o parecer médico e os registros, asseguravam, circunscrevendo e ou indicando, conforme documentos em prontuários das alunas, em um primeiro momento, exclusivamente, o diagnóstico inicial de Transtorno Mental e, encontrava-se em tratamento psiquiátrico, conforme informação verbal da Coordenadora do Programa. Assim, entrevistaram-se as mães das seguintes alunas ${ }^{2}$ :

1) Lélia (D1), sexo feminino, dez anos, aluna de Classe de Apoio / Educação Infantil, com diagnóstico de Transtorno Desintegrativo da Infância com características Psicóticas [F84.3]; com acompanhamento psiquiátrico (convênio privado) e psicológico em unidade de saúde pública municipal e prescrição medicamentosa de Haldol. Freqüentou a partir de 2001, a Sala de Recursos do Programa de Educação Especial, em período contrário ao da Pré-Escola. Em 2002, foi matriculada em período integral e, exclusivamente, no Programa de Educação Especial que passou a freqüentar regularmente.

2) Íris (D2), sexo feminino, 14 anos, aluna de Oficina Pedagógica, com registro de diagnóstico de Esquizofrenia e com acompanhamento em unidade de saúde pública municipal nos setores de Psiquiatria e Terapia Ocupacional; não havia registro de prescrição medicamentosa. Freqüentou a Pré-Escola, posteriormente o Ensino Fundamental regular comum e foi matriculada, em 1999, em período integral e, exclusivamente, no Programa de Educação Especial, onde permaneceu desde então.

\section{Procedimentos de Coleta e Análise dos Dados}

Os aspectos éticos foram cumpridos, conforme as Resoluções do Conselho Nacional de Saúde (CNS) dispostas por meio da Resolução n. ${ }^{\circ}$ 96, de 10 de outubro de 1996 (Brasil, 1996), que aprovou as diretrizes e normas regulamentadoras

2 Identificação fictícia para manter o anonimato dos nomes das alunas. de pesquisa, envolvendo seres humanos (Brasil, 1996). A pesquisa foi aprovada pelo Comitê de Ética da Escola de Enfermagem da Universidade de São Paulo e autorizada pela Secretaria Municipal de Educação.

Para a análise dos discursos dos entrevistados, foi utilizada a proposta de Análise de Conteúdo de Bardin (1994), definida por ela como um "conjunto de técnicas de análise de comunicações" (p. 42) que, por meio de procedimentos sistemáticos e objetivos de descrição do conteúdo dos dados coletados, possibilita a inferência de conhecimentos que se referem às condições de produção e ou recepção (variáveis inferidas) das comunicações.

\section{Resultados}

Entre as muitas questões para estudo que acabaram por emergir, destaca-se aquela em que o familiar revelaria o seu entendimento frente à perspectiva de retorno do filho ao ensino regular comum.

Portanto, para a mãe de Lélia, a perspectiva da inclusão escolar na rede regular comum:"“.. seria uma tentativa?..." (D1.37). Justificada por ela em razão da filha:“... ela não sabe escrever nada." (D1.38). Por outro lado, a mãe de Íris relatou: "é... eu fiquei pensando nisso o ano passado quando ela terminou no ano passado...” (D2.33). Pois, “... será que a minha filha vai ficar sempre só freqüentando aqui... não vai ter condição nunca de freqüentar uma escola normal..." (D2.34), “... aí, eu fico pensando, mas... do jeito que ela está como ela vai ter condição de freqüentar uma escola normal..." (D2.35). No entanto, para esta mãe:“"... podia até tentar não é? Para ver como ela se comporta agora não é? Depois desse tempo todo, não é?" (D2.36).

A análise desta categoria indicou que as mães da alunas representaram a perspectiva de inclusão escolar como uma tentativa, uma vez que as alunas não estavam, ainda, alfabetizadas. Entretanto, encontramos que nas proposições Educação Inclusiva haveria um lugar para Lélia e Íris, uma vez que implicaria:

... uma reforma radical nas escolas em termos de currículo, avaliação, pedagogia e formas de agrupamento dos alunos nas atividades de sala de aula. Ela é baseada em um sistema de valores que faz com que todos se sintam bem-vindos e celebra a diversidade que tem como base o gênero, a nacionalidade, a raça, a linguagem de origem, o background social, o nível de aquisição educacional ou a deficiência (Mittler, 2003, p. 34).

A educação inclusiva é uma aplicação prática de um movimento mundial denominado de inclusão social que propõe um novo paradigma e implica um processo bilateral, das pessoas excluídas e da sociedade, na construção de uma parceria que busca efetivar a equiparação de oportunidades (Mendes, 2002). Nesse sentido, embora o debate sobre a educação inclusiva não tenha nascido no contexto da educação especial, se aplica também a ela, na medida em que sua clientela também faz parte daquela população historicamente excluída da escola e da sociedade (Mendes, 2002).

Para melhor compreender, a importância da ampliação da proposição de uma sociedade inclusiva, ao entrevistar 
as mães, foi possível, ainda, entender a dialética exclusão/ inclusão, pois as duas alunas haviam freqüentado a Pré-escola (Educação Infantil). Embora, a legislação brasileira vigente na época não obrigasse a matrícula escolar da criança na faixa etária até seis anos e 11 meses, ambas possuíam um antecedente de freqüência na modalidade de Educação Infantil, relatado por uma das mães:"Ela estudou na Escola... é prezinho também..." (D1.4).

Por outro lado, foi na Pré-escola que as alunas apresentaram comportamentos diferenciados mais acentuados, que foram assim pontuados pelas mães, “... desde os quatro aninhos que ela está na escolinha, mas ela nunca teve progresso nenhum..." (D1.5)“...quando ela entrou no prezinho que ela começou com essas dificuldades aí...” (D2.38)

Essas mães representaram, ainda, o período da Pré-escola, como um espaço lúdico, mas também de proposições pedagógicas. Para a mãe de Lélia, nos momentos de brincadeira:“... ela conseguia ficar" (D1.10)

No entanto, “...na hora de fazer alguma atividade, algum desenho, ela se recusava..." (D1.11).Por outro lado, a mãe de Íris relatou que independente das atividades propostas, “...ela atormentava muito as outras crianças, atrapalhava as crianças no que elas estavam fazendo, negócio de, às vezes, beliscar, puxar cabelo, tirava a atenção das crianças" (D2.4)

Naquele período, a relação com as professoras foram, assim, descritas: para a mãe de Lélia “...ela ficava num cantinho, e lá ela ficava...” (D1.12) e “...nunca participou de desenhar" (D1.13).

Já para a mãe de Íris, sua filha apresentava o seguinte comportamento:“...ficava só atrás da professora, ela fazia lição e... fazia ali... às vezes, de desenhar ou pintar alguma coisa ou ela rasgava, ou ela amassava...” (D2.7).Ainda,“... ficava só ali, atrás da professora... chegava uma hora que ela ficava rodando, só queria ficar atrás da professora..." (D2.8). Somando-se a isso, “...na época, eu não sei se ela chegou cuspir, mas, mais tarde ela começou com esse negócio de cuspir..." (D2.5).No contexto pré-escolar, a mãe de Lélia, entendeu que:“....bom ela estudava na escolinha só que lá eles acharam que não era problema de lá...” (D1.7).

Naquele momento, por indicação da Unidade Escolar e por meio do Grupo de Apoio Pedagógico (GAP) da Secretaria Municipal de Educação (SEME),“...ela estava fazendo tratamento no Departamento de Reabilitação Física e Mental (DEREFIM) com a Psicóloga...” (D1.14) e,“...foi ela que indicou essa Escola [Programa de Apoio à Educação Especial - PAEE] aqui..." (D1.15).Naquele período a mãe relatou ter havido um momento de discussão intersetorial:"Fez uma vez... [...] foi a doutora, que é psicóloga do Departamento de Reabilitação Física e Mental (DEREFIM), com a professora que ela estudava." (D1.72).

Como resultado da discussão, houve a indicação, por meio de laudo psicológico do Departamento de Reabilitação Física e Mental (DEREFIM), que a aluna, em horário contrário ao da Pré-escola, começou a freqüentar o Programa de Apoio à Educação Especial (PAEE). Foi interessante constatar que essa mãe passou a representar o Programa como uma proposta escolar, pois:“...ela começou a freqüentar a escolinha, enquanto que estava no pré... [...] brincando...” (D1.9).

Nesse ponto, observa-se uma confusão e ambigüidade na fala dessa mãe, pois, para ela o papel da Educação Infantil, tanto poderia representar um espaço somente para brincadeiras, como um espaço de aprendizagem e, ainda, um misto entre um e outro.

A experiência da mãe de Íris, no contexto pré-escolar, frente aos comportamentos e atitudes da filha, foi relatada da seguinte maneira: “...na época do prezinho... eu não estava levando ela em lugar nenhum..." (D2.39).

Entretanto: “...quando ela foi indicada, quando eu coloquei ela no prezinho, quando ela não estava se enturmando lá, estava dando problemas, eles indicaram para mim levar no Programa de Apoio à Educação Especial (PAEE)...” (D2.1).

Em sua fala ficou claro, haver sido orientada a importância da filha receber assistência, no caso, freqüentar em horário contrário ao da Pré-escola, a Sala de Recursos do Programa de Apoio à Educação Especial (PAEE), a mãe ressaltou:“...eu, não aceitei muito porque... ficava naquela, eu não queria.... aceitar dela ir para uma escola especial...” (D2.2).“....achava que com o tempo isso aí ia... ela ia melhorar, que ia acabar freqüentando a escola normal e, na época, pela dificuldade que eu tinha, eu acabei não levando,ela estava no prézinho, porque na época não tinha perua nem para pegar nem para levar de volta..." (D2.3),

Para Jerusalinsky (1997), o papel da escola é fundamental, pois é nesse espaço de entrar e sair, um lugar de trânsito, que faz dela uma instituição "normal" da sociedade, não estando representada socialmente como um depósito, como o é um hospital psiquiátrico. Nesse sentido, espera-se de alguém, que ao freqüentar a escola sinta-se mais reconhecido socialmente do que aquele que não freqüenta. Pois, é assim que, muitos "psicóticos púberes ou adolescentes, reclamam que querem ir à escola com seus irmãos, precisamente porque isso funcionaria para eles, como um signo de reconhecimento de serem capazes de circular, numa certa porção, pela norma social" (Jerusalinsky ,1997, p. 91).

\section{Discussão}

A contribuição e relevância deste estudo devem-se ao fato de que as questões que envolvem a construção da doença mental têm sofrido modificações ao longo da história humana em um processo histórico-estrutural de exclusão/inclusão, portanto, com verdades historicamente produzidas e variadas.

Por outro lado, existe uma idéia subjacente de que a loucura não é parte da esfera ou de competência, também, das proposições do processo ensino e ou aprendizagem regular ou especial e, ainda, servindo para fortalecimento de paradigmas que estabelecem uma linha divisória entre "normal" e "anormal".

Com a educação inclusiva, é necessário romper com paradigmas, a fim de estabelecer um novo lugar escolar implicado na diversidade e que a segregação de alunos e o distanciamento mútuo entre família e escola, não são mais possíveis. Ainda, há uma necessidade premente de ações intersetoriais e de complementaridade de ações, sobretudo na formulação e implementação das políticas públicas. Assim, justifica-se a importância deste estudo em razão de, historicamente, sempre houve uma tendência da instituição escolar de homogeneizar seus alunos, sendo a educação inclusiva, antes de tudo, uma provocação que propõe uma educação 
para todos, sem exceção. As propostas político-pedagógicas, assim como o cotidiano escolar em seus processos pedagógicos e de avaliação do desenvolvimento do aluno, segundo as concepções da educação inclusiva, também, devem ser submetidas a um novo olhar e distintas práticas.

Ensino/aprendizagem é chamada para participar efetivamente do desenvolvimento escolar em todos os seus aspectos. Isso dado, espera-se com esse estudo que a unidade escolar frente à organização e execução das proposições da educação inclusiva, além de buscar ou ampliar sua articulação com a família do aluno com transtorno mental, venha a contribuir para um trabalho produtivo com as diferenças, conflitos, desentendimentos e desestabilizações que implicam as relações com a diferença, especialmente, se considerarmos que as políticas intersetoriais que envolvem as áreas de educação, de saúde e social precisam ser revistas e ampliadas.

$\mathrm{Na}$ especificidade deste estudo, encontram-se alguns caminhos para melhor entender a problemática que envolve a criança e o adolescente em tratamento psiquiátrico. Couto (2001) cita que haveria três mal entendidos: o mal entendido pedagógico, o mal entendido que se refere à justiça e o mal entendido da saúde mental.

O mal entendido pedagógico é o que reduziria a criança à condição de aprendiz, que acaba por sustentar um "[...] ideário de metas a serem alcançadas de tal forma que ela, a criança, possa ser medida em escalas de desenvolvimento e recolocada no curso do desenvolvimento saudável caso apresente algum desvio" (Couto, 2001, p.137). Assim, inseridas em um contexto educacional, supúnhamos que estariam a salvo do reducionismo médico; no entanto, as crianças e adolescentes ficaram, "na verdade excluídas das tentativas de construção de um dispositivo clínico/psicossocial que desse sustentação a um novo modo de cuidar dirigido a sujeitos em sofrimento e não a aprendizes eficazes" (Couto, 2001, p.137).

$\mathrm{O}$ segundo mal-entendido refere-se à justiça que acaba por envolver esses sujeitos em um enquadre de tutela e de proteção. A transformação, neste caso, seria mais do que buscar a construção de novas modalidades de serviços seja na educação, na saúde ou dos benefícios sociais para o cuidado de crianças e adolescentes, seria, "fundamentalmente, rever e reescrever as fundações conceituais do exercício da tutela, sem o quê tudo terá sido inócuo" (Couto, 2001, p. 137).

O terceiro equívoco foi nomeado pela autora, provisoriamente, como mal-entendido da Saúde Mental. Este diz respeito à desconsideração de que uma criança possa portar o enigma da loucura. "Criança deficiente e desadaptada sim, louca não; parecem bradar os fios da história em suas traduções quotidianas nos serviços assistenciais existentes" (Couto, 2001, p. 137). A autora ainda aponta que "tributar a uma criança a enigmática condição de uma existência particular, louca, exige um duro exercício de rompimento com os ideais que na modernidade sustentaram sua inclusão diferenciada e valorada na cena social" (Couto, 2001, p.137), visto que esta posição de "criança louca" acaba por macular os ideais, subvertendo o imaginário cultural, o que acaba por nos convocar ao desafio de delas cuidar e com elas coexistir.

Uma dura resistência freqüentemente formulada num falso democratismo que confunde uma questão de sintoma com uma questão de direito, ora num igualitarismo puramente imaginário, muito mais destinado a satisfazer o narcisismo dos pais ou as aparências políticas do que as verdadeiras necessidades clínicas das crianças que padecem destas dificuldades (Jerusalinsky ,1997, p. 93).

Em termos de desenvolvimento, não se pode ignorar o fato de que:

... e alguns psicóticos adultos tiveram a chance de produzir, em períodos fora de crise, algumas suplências de laço que lhes permitiram estudar, aprender uma profissão e eventualmente ter uma circulação social, muitas crianças não têm a mesma sorte. A interrupção do desenvolvimento as captura em um momento anterior a qualquer aprendizagem, ainda que frágil ou suplente, do universo social (Kupfer \& Petri, 2000, p. 113).

Nesse sentido, percebe-se que a tendência social de exclusão do deficiente e do louco passava, ainda, pela instituição escolar. "Aquela em já havia sido apontada a vocação segregacionista a propósito dos pobres, agora recebia também o impacto da crítica de segregação aos loucos e diferentes" (Voltolini, 2004). Ou seja,

... que se fala em louco, e não em psicótico, por exemplo, ou ainda, em crianças portadoras de necessidades educativas especiais, e não em psicóticos, autistas, cegos, surdos, etc., já que se trata não da prática e da teorização específicas com estas pessoas, mas sim do funcionamento dos diversos discursos (científico, religioso, político, etc.) que atribuem a estas crianças seu estatuto (Voltolini, 2004, p. 94).

Por outro lado, entende-se que,

... a construção do direito de cidadania como eixo prioritário não é uma escolha somente ética, mas também técnica: somente o cidadão pleno poderá exercitar as suas trocas (e com essas trocar também a loucura), enquanto o cidadão partido ao meio não saberá o que fazer com as aquisições (se na verdade adquiridas), com as habilidades relacionais, uma vez que não haverá direito nem acesso ao exercício de relações ou estas se darão como relações desprovidas da materialidade que as torna reais (Saraceno, 1999, p. 94).

Dessa forma, as ações deverão estar voltadas para criança-sujeito, "na condição de estar vivenciando a complexa experiência de um sofrimento para ela intolerável, sejam quais forem às formas escolhidas para a expressão de sua dor; do fracasso na escola ao horror do olhar" (Couto, 2001, p. 142). Assim, se faz necessária à construção de noções e conceitos como "existência-sofrimento" do sujeito na sua relação com o corpo social, paradigma estético, acolhimento, cuidado, emancipação e contratualidade social (Costa-Rosa, Luzio \& Yasui, 2003).

Ainda que existam inúmeros textos de Relatórios, Conferências, Declarações, Protocolos Legais, entre outros - na Educação e na Saúde - que indiquem a importância da intersetorialidade para a compreensão na busca de qualidade na atenção e a necessidade de ressignificação da vida dos sujeitos em sofrimento psíquico, os depoimentos das mães mostraram que os profissionais das áreas de educação e saúde passam ao largo dessas informações e orientações. 
De forma a garantir e ampliar o desenvolvimento dessas alunas no contexto do Programa de Educação Especial ou para lhes possibilitar uma inclusão em classe comum da rede regular de ensino, far-se-á necessário, primeiro, que se busque uma intervenção pedagógica que efetive e garanta o acesso dessas alunas na aquisição da leitura e da escrita, além de repensar as relações interpessoais que estão estabelecidas entre elas e o grupo.

Acredita-se que, em casos singulares como estes, por meio de um Plano de Ensino Individualizado (PEI) o professor ao estabelecer de dois a três objetivos que, efetivamente, possam garantir um desenvolvimento significativo no processo de aprendizagem, poderiam reconduzir, reorientar, ampliar e ressignificar o movimento educacional dessas alunas.

Em segundo, que ocorram discussões intersetoriais entre profissionais da escola e da saúde, para assim, garantir que a essas alunas lhes seja facultado o direito de que suas existências-sofrimento sejam minimizados, assim como ampliar, aprimorar e melhorar os vínculos com essas famílias, de forma a garantir que acessem outros meios de relações possíveis na comunidade.

Por fim, considera-se que, com as proposições da Educação Inclusiva, a partir da década de 1990, deve-se buscar a defesa esse movimento, como parte de um processo maior que é o da inclusão social, e atuar no sentido de garantir a universalização do acesso e da qualidade dos contextos sócio-educacionais. Por outro lado, o Estudo de Caso proposto, em sua especificidade, mostra que a viabilidade das proposições da Educação Inclusiva só dará certo se ocorrer quebra de paradigma em torno do doente mental.

\section{Referências}

Ainscow, M. (2005). El próximo gran reto: la mejora de la escuela inclusiva [Presentación de apertura del Congreso sobre Efectividad y Mejora Escolar; ene.; Barcelona].

Bardin, L. (1994). Análise de Conteúdo. Lisboa: Edição 70.

Brasil (1996). Conselho Nacional de Saúde. Resolução nº 196, de 10 de outubro de 1996. Aprova as Diretrizes e Normas regulamentadoras de pesquisas envolvendo seres humanos.

Brasil (2004a). Educação inclusiva: V.1: A fundamentação filosófica. Brasília: Ministério da Educação, Secretaria de Educação Especial.

Brasil (2004b). Direito à educação: subsídios para a gestão de sistemas educacionais: orientações gerais e marcos legais. Brasília: Ministério da Educação, Secretaria de Educação Especial.

Brasil (2002). Ministério da Saúde. Portaria $n^{\circ}$ 1.060/GM de 05 de junho de 2002, que aprova, em forma de Anexo, a Política Nacional de Saúde da Pessoa Portadora de Deficiência. Retrieved from http://dtr2001.saude.gov.br/sas/PORTARIAS/ Port $2002 / \mathrm{Gm} / \mathrm{GM}-1060$.htm

Cavalheri, S. C. (2003). Acolhimento e orientação à Família. Mesa Redonda: Importância da Família na Saúde Mental. Retrieved from http://www.sppc.med.br \mesas \silvana.htm

Costa-Rosa, A. C., Luzio, C. A., \& Yasui, S. (2003). Atenção Psicossocial: rumo a um novo paradigma na saúde mental coletiva. Archivos de Saúde Mental e Atenção Psicossocial, 1, 13-44.
Couto, M. C. V. (2001). Novos desafios à Reforma Psiquiátrica Brasileira: necessidade da construção de uma política pública de saúde mental para crianças e adolescentes. In Ministério da Saúde. Conselho Nacional de Saúde. Caderno de Textos de Apoio da III Conferência Nacional de Saúde Mental (pp.133142). Brasília: Ministério da Saúde / Conselho Nacional de Saúde.

FGV/IBR/CPS. (2004). Fundação Getúlio Vargas. Instituto Brasileiro de Economia. Centro de Políticas Sociais. Retratos da deficiencia no Brasil (PPD). Retrieved from http//fgv/cps.

Houaiss, A. E., \& Villar, M. S. (2001). Dicionário Houaiss da Língua Portuguesa. Rio de Janeiro: Objetiva.

Ferretti, J. S. E.; Milan, T. R. C., \& Sanches, A. C. G. (2004). Proposta Pedagógica Global da Rede Municipal de Ensino de Indaiatuba. Secretaria Municipal de Educação. Indaiatuba: Caravela.

Jerusalinsky, A. (1997). A escolarização de crianças psicóticas. Estilos da Clínica. Revista sobre a infância com problemas, 2, 72-95.

Jovchelovitch, S. (2000). Representações sociais e esfera pública: a construção simbólica dos espaços públicos no Brasil. Petrópolis: Vozes.

Kupfer, M. C. M., \& Petri, R. (2000). "Por que ensinar a quem não aprende?". Estilos da Clínica. Revista sobre a infância com problemas, 9, 109-117.

Melman, J. (2001). Família e doença mental: repensando a relação entre profissionais de saúde e familiares. São Paulo: Escrituras.

Mendes, E. G. (2002). Perspectivas para a construção da Escola Inclusiva no Brasil. In M. S. Palhares \& S. C. Marins (Eds.), Escola Inclusiva (pp. 61-85). São Carlos: EdUFSCar.

Minto, C. A. (2002). Educação Especial: da LDN aos Planos Nacionais de Educação - MEC e Proposta da Sociedade Brasileira. In M. S. Palhares \& S. C. Marins (Eds.), Escola Inclusiva (pp. 11-39). São Carlos: EdUFSCar.

Mittler, P. (2003). Educação Inclusiva: contextos sociais. Porto Alegre: Artmed.

Neder, G. (2002). Ajustando o foco das lentes: um novo olhar sobre a organização das famílias no Brasil. In S. M. Kaloustian (Ed.), Família brasileira, a base de tudo (pp. 26-46). São Paulo: Cortez.

OMS. Organização Mundial da Saúde. (1993). Classificação de Transtornos Mentais e de Comportamento da CID-10. Porto Alegre: Artes Médicas.

OPAS/OMS. (2001). Organização Pan-Americana de Saúde. Organização Mundial de Saúde. Relatório sobre a Saúde no Mundo 2001: Saúde mental: Nova Concepção, Nova Esperança. Retrieved from http//www.acs.min-saude.pt/ files/2008/03/rel-mundial-sm-2001.pdf

Prieto, R. G. (2003). Políticas públicas de inclusão: compromissos do poder público, da escola e dos professores. Revista Educativa APEOESP. Retrieved from http://educacaoonline. pro.br

Sá, C. P. (1998). A construção do objeto de pesquisa em representações sociais. Rio de Janeiro: EdUERJ.

Saraceno, B. (1999). Libertando Identidades. Da reabilitação psicossocial à cidadania possível. Rio de Janeiro: Te Corá / Instituto Franco Basaglia.

Sassaki, R. K. (2003). Inclusão. Construindo uma sociedade para todos ( $5^{\mathrm{a}}$ ed.). Rio de Janeiro: WVA. 
Stainback, S., \& Stainback, W. (1999). Inclusão: um guia para educadores. Porto Alegre: Artes Médicas Sul.

UNESCO. (1990). Declaração Mundial sobre Educação para Todos. Jomtien: Tailândia.

UNESCO. (1994). Declaração de Salamanca e Enquadramento da Ação na área das necessidades educativas especiais. Conferência Mundial sobre necessidades educativas especiais: acesso e qualidade.

Voltolini, R. (2004) Psicanálise e Inclusão Escolar: direito ou sintoma? Estilos da Clínica. Revista sobre a infância com problemas; 16, 92-101.
Recebido em 23.04.2009

Primeira decisão editorial em 14.06.2009

Versão final em 20.05.2011

Aceito em 14.09.2011

\section{REUNIÃO ANUAL DA SOCIEDADE BRASILEIRA DE PSICOLOGIA FORMAÇÃO E PRODUÇÃO DO CONHECIMENTO EM PSICOLOGIA}

29 de Outubro de 2011

Belém, PA, BR 